\title{
Does female education explain the disparity in the use of antenatal and natal services in Nigeria? Evidence from demographic and health survey data.
}

\author{
Abubakar Sadiq Umar
}

Walden University, School of Public Health, College of Health Sciences.

\begin{abstract}
Background: Nigeria is among the countries with a high number of annual maternal deaths partly due to low utilization of maternal health services (MHS).

Objective: This study aimed to explore whether there is an association between women's level of education and the appropriate use of antenatal and delivery services.

Method: A quantitative cross-sectional study was used to analyze the Nigerian Demographic and Health Survey (NDHS) data. Information from 33,385 women aged 15 - 49 years was analyzed using Bivariate Pearson Chi square test and multiple logistic regressions.

Results: Education is statistically associated with the number of antenatal clinic visits made (AOR = 3.208; CI 2.875 - 3.578; p $<.0001)$ and the place of delivery (AOR $=2.009$; CI 1.449 $-2.785 ; \mathrm{p}<.0001)$ even after controlling for availability of skilled health workers, parity, income, religion, age and distance.

Conclusion: A long term investment in girls' education will improve income, interaction with health care providers, level of autonomy to seek and pay for appropriate MHS and ultimately use of MHS and positive pregnancy outcomes.

Keywords: Education, antenatal, delivery, Nigeria.

DOI: https://dx.doi.org/10.4314/ahs.v17i2.13

Cite as: Umar AS. Does female education explain the disparity in the use of antenatal and natal services in Nigeria? Evidence from demographic and health survey data. Afri Health Sci. 2017;17(2): 391-399. https:// dx.doi.org/10.4314/abs.v17i2.13
\end{abstract}

\section{Introduction}

Maternal mortality remains one of the major causes of death among women in the reproductive age group in the developing countries. From time immemorial, serious concern has been raised on how to improve access and utilization of antenatal and delivery services in order to reduce pregnancy related morbidity, deaths and disability. In 2003, the World Health Organization (WHO) estimated that, 289,000 women died as a result of pregnancy related complications ${ }^{1}$, showing an additional 2,000 maternal deaths ${ }^{2}$ higher than what was recorded in 2011. Almost all (99\%) of these deaths occur in the developing countries among the rural, poor, and illiterate women ${ }^{1}$.
Corresponding author:
Abubakar Sadiq Umar,
Walden University,
School of Public Health,
College of Health Sciences.
Email: abubakar.umar@waldenu.edu,
ausadiq@yahoo.com

Moreover, about two-thirds of the estimated annual maternal deaths were from five South East Asian countries (Afghanistan, Bangladesh, India, Indonesia, and Pakistan) and six African countries namely Democratic Republic of the Congo, Ethiopia, Kenya, Nigeria, Sudan, and Tanzania $^{1,2,3,4}$. By extension, it means maternal death is recorded every two minutes in the developing countries and hence, women living in the developing world are at higher life time risk of dying as a result of pregnancy related complications. For instance, current estimates showed that the lifetime risk of a Nigerian woman dying as a result of pregnancy related morbidity is 1 in 23 compared to Australia and Ireland at 1 in 17, 800 and Greece at 1 in 31,800 respectively, signifying between 17,000 - 20,000 fold disparity between Nigeria and these developed countries ${ }^{2}$.

Maternal mortality ratio (MMR) is the number of maternal deaths per 100,000 live births ${ }^{1}$. It is a pointer of the status of women in any community, the state of their health, and the degree of access to the MHS. Although, progress has been recorded in reducing these avoidable deaths by local and international efforts such as the Safe 
motherhood Initiative, Making Pregnancies Safer, Millennium Development Goal 5 (MDG) and currently Sustainable Development Goal 3 (SDG 3), however, none of the high burden countries in South East Asian and sub-Saharan African countries mentioned above have achieved a reduction in Maternal Mortality Ratio (MMR) by twothirds when compared with figures of the $1990^{4}$. The target of SDG 3 is to achieve a Maternal Mortality Ratio of 140/100,000 live births by 2030 for the high burden countries ${ }^{4}$. However, it is important to note that by the end of 2015, these high burden countries have not been able to achieve the target set for MDG 5 of 300 maternal deaths per 100,000 live births ${ }^{4}$. Most disturbing is the fact that monitoring of progress towards achieving the MDG 5 revealed that, there are huge disparities within and between the various parts of a given country ${ }^{5}$.

One reason that is central to the observed disparities in the use of modern health care services within and between the various parts of any given country is the level of educational attainment of the pregnant woman. Education is known to influence a woman's worldview ${ }^{6,7}$, readiness to accept modern obstetric care ${ }^{4}$, capacity to participate in the decision making process on issues relating to her health ${ }^{8,9}$, economic independence ${ }^{10,11}$ and her overall health cultural capital ${ }^{12}$. Pooled data from 2005 to 2010 shows the global adult literacy rate of $84 \%$, with the lowest rate of $63 \%$ from sub-Saharan Africa ${ }^{2}$. It is pertinent to note that, disparities in literacy were well documented within the African region, with the West African countries (Nigeria belongs to this region) of Mali, Niger, Senegal, and Sierra Leone having the lowest literacy rates with more than $50 \%$ of women in the reproductive age (15-49 years) having formal education (unable to read or write) and a high $\mathrm{MMR}^{2}$.

The current female literacy rate for Nigeria ${ }^{2}$ was estimated at $61 \%$. However, differences exist between the six political zones that were drawn based on commonality in ethnic, religious and cultural inclination. Some states in the North Eastern and North Western zones of Nigeria have more than two-thirds of the female population as stalk illiterates ${ }^{32}$. Interestingly, studies on maternal mortality in some states of these zones have reported an MMR of up to 1,791 per 100,000 live births ${ }^{13,14}$ which nearly doubled reports from the Southern part of Nigeria $^{15,16}$. While education is related to socio-economic class, nevertheless, data shows it influences health behavior and the utilization of health services when income level was controlled ${ }^{9,11,17-24}$. Studies have demonstrated that women who have gone beyond the primary school level are more likely to have higher number of ante-natal clinic visits and deliver in a health facility compared to unschooled wom$\mathrm{en}^{9,11,17,18}$. However, other studies have shown that educational attainment does not always lead to appropriate use of health services ${ }^{25}$. For example, educated people were found to miss follow up visits, fail to comply with full treatment regimen and more comply to self-prescribed regimens compared to their illiterate colleagues that belong to similar socio-economic levels or reside in similar neighborhoods ${ }^{25}$. Furthermore, it has been reported that uneducated women account for disproportionately high maternal and neonatal morbidity, mortality and disabilities due in part to their low health cultural capital and lack of autonomous status to negotiate their reproductive rights within the family structure ${ }^{22,23,24,26}$. In Nigeria ${ }^{11,27,28}$ and other parts of the world, ${ }^{3,29}$ raising levels of education delays age at marriage and age at first delivery while increasing opportunities for better paying jobs. Studies in India, ${ }^{30}$ Kenya $^{31}$ and elsewhere ${ }^{32}$ have demonstrated that delaying child bearing until women are between the age of 20 - 30 years was reported to have a fourfold lower risk of dying from pregnancy related complications compared to those less than 20 years old. Furthermore, women in the developed countries delay child bearing and have few number of children compared to the high fertility rate of 5 or more in the sub-Saharan African countries.

Overall, the level of educational attainment enhances the ability of a woman to overcome negative cultural norms, enhance her skills to bargain for autonomy within the family and community structure and ultimately take appropriate health related actions compared to her illiterate counterpart ${ }^{33}$. Given the significant disparities in the level of female literacy and MMR among the various parts of Nigeria as highlighted above, this study aimed to explore whether the use of ante-natal and delivery services is influenced by the educational attainment of the Nigerian women. Findings of the study will add to the available data on maternal health with potential to improve data driven planning, implementation and ultimately high-use rate of MHS. The theoretical framework of the study was based on the Anderson health utilization model which provides constructs on personal, community and health system characteristics ${ }^{34}$. 


\section{Methods}

The study design was cross-sectional using the Nigerian demographic and health survey (DHS) data to test whether there is significant statistical association between a woman's level of education and the use of MHS as mea- sured by the number of antenatal visits ( $<4$ or $\geq 4$ visits) and place of delivery (home or health facility). A two stage cluster proportionate to size sampling technique was used to recruit 33,385 women from all the 36 states and the federal capital territory which were clustered into 6 geopolitical zones (Figure 1).

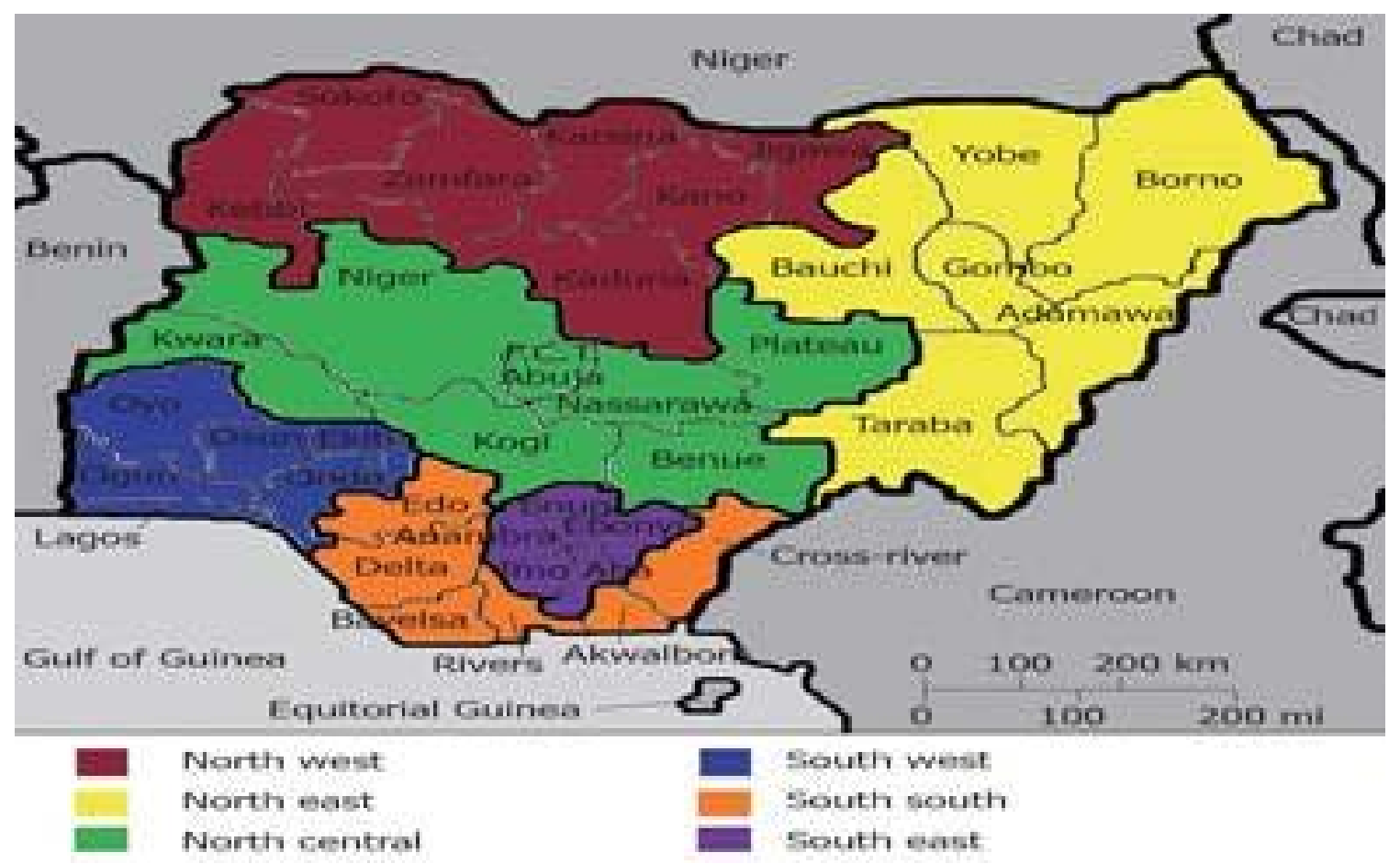

Figure 1: Map of Nigeria showing the six geopolitical zones and states

The information collected during the survey covered all the Millennium Development Goals (MDGS). Details of the survey method can be obtained from the survey report available online ${ }^{35}$. Periodic DHS are currently conducted in over 70 countries from 1984 to date to provide uniform data for international comparison within and between countries. ${ }^{36}$ Bivariate Pearson's Chi-square test statistic and two stages of Multivariate regression analysis were conducted. The number of ANC visits made during the pregnancy before the survey was coded as 0 for those that had reported having made less than four visits while women who made a minimum of four visits as recommended by $\mathrm{WHO}^{3}$ were coded as 1 and compared to the former. The place of delivery was categorized as home (coded as 0 ) and institutional (coded as 1) and comparison was with home as the reference population. The level of education was coded as 1 for those with no formal education, code 2 for Primary level, code 3 for Secondary (high school) level, and code 4 for post-secondary (high school) levels. Women with no formal education were the reference group.
Confounding variables that were controlled when assessing whether there was significant statistical association between a woman's level of education and the use of MHS included availability of skilled health worker, distance, parity, income, religion, age and distance. These variables were chosen based on well-known predictors from published works ${ }^{6,7,10,11,27}$ and / or were observed to be statistically significant on Pearson chi-square statistic. ${ }^{37}$ The unadjusted and adjusted odd ratios from the regression analysis were estimated at 95\% confidence interval, which was the critical value when the hypothesis was tested.

\section{Ethical consideration}

The custodian of the DHS data - ORC Macro and ICF International based in Calverton Maryland, USA granted the permission to use the DHS data. The Institutional Review Board (IRB) of Walden University Minneapolis, MN 55401, USA approved this study via approval number 01-23-15-03386 ${ }^{13}$. 


\section{Results}

The female literacy rate by zones in order of increasing magnitude showed North West 32.5\%; North East $34.5 \%$; North Central $60.7 \%$, South-South $78.5 \%$, South East $78.2 \%$ and South West $85.1 \%$.

A high percentage of women (40\%) and husbands/partners $(43 \%)$ had no formal education. Only $7.9 \%$ of re- spondents and $11.8 \%$ of their husbands/partners had more than secondary (high school) level of education respectively (Table 1). Further analyses revealed that less than $5 \%$ of all women that had more than 12 years of formal education, which is equivalent to the completion of senior secondary school level (high school) based on the National Education Policy ${ }^{35}$.

\section{Table 1: Educational characteristics of respondents}

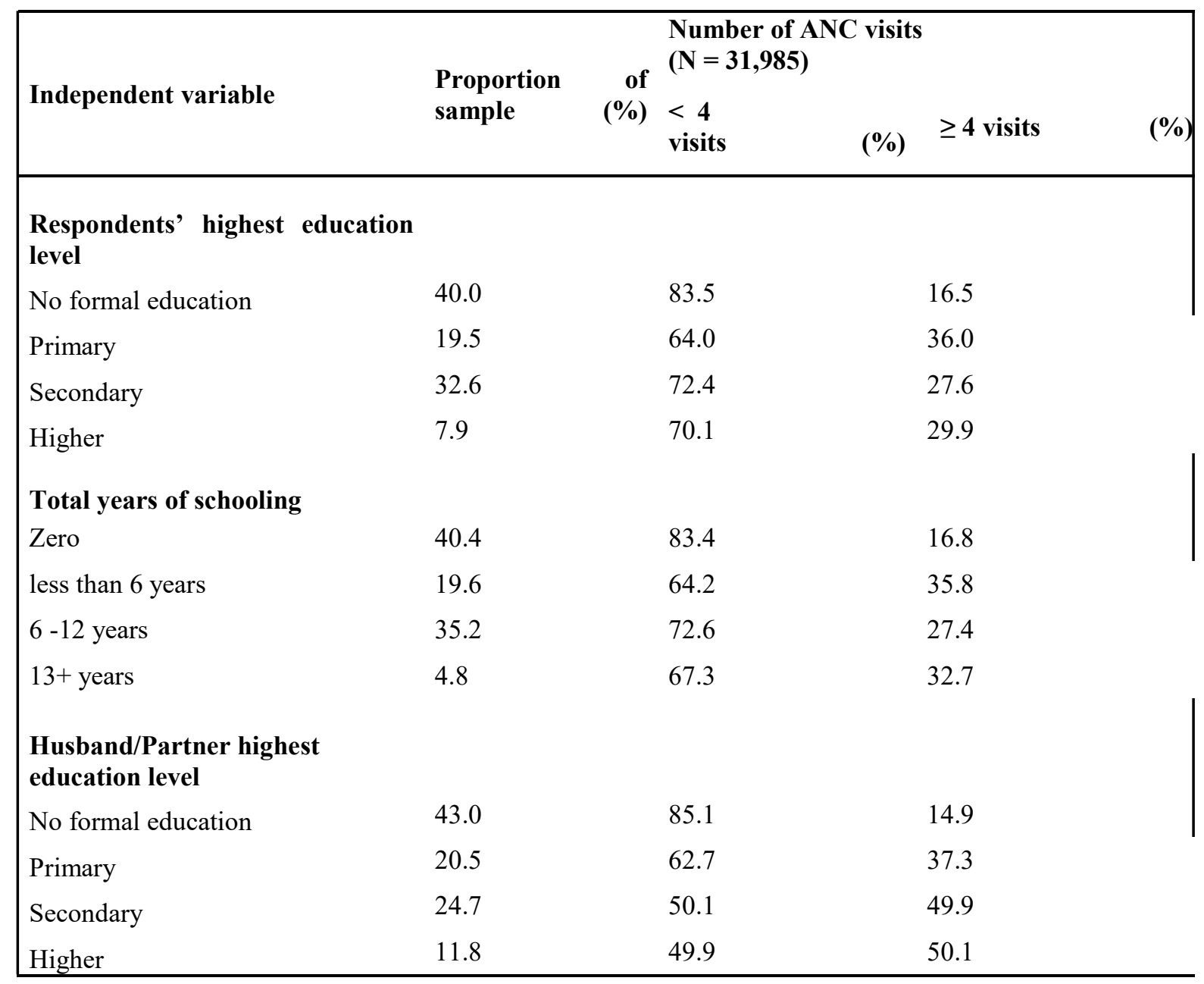

The proportion of women who had four or more antenatal visits was higher for educated women when compared to those with no formal education, irrespective of the level of educational attainment (Figure 2). 


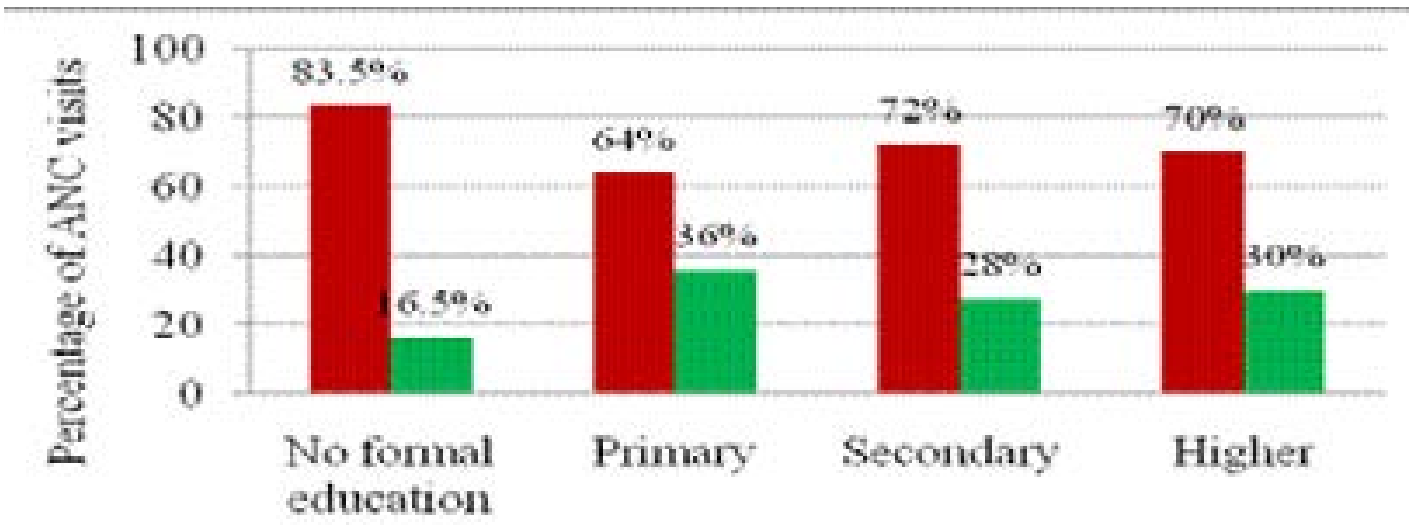

\section{Categoty of ANC visits by respondents level of education \\ 44 ANC visits $m>$ or $=4$ ANC visits}

Figure 2: Level of education and the number of antenatal visits made.

Education was found to be statistically associated with the use of antenatal services $(\chi 2=972.025$; $\mathrm{df}=3$; $\mathrm{p}<$ .001). Women who had completed primary school have more than two folds more likelihood of achieving the minimum recommended four antenatal clinic (ANC) visits compared to their uneducated counterparts (UOR = 2.856; CI 2.664 - 3.062). The use of antenatal services was found to increase with increasing level of education $\left(\chi^{2}=2696.057 ; \mathrm{df}=3 ; \mathrm{p}<.001\right)$ (Table 2). Moreover, women whose husbands/partners have gone beyond primary level of education were more likely to achieve the minimum recommended number of ANC visits by at least five folds compared to women whose husbands / partners were illiterate (UOR $=5.691$; CI 5.28 - 6.134). The positive impact of women's education on the use of ANC services remained similar after controlling for confounders $(\mathrm{AOR}=3.208 ; \mathrm{CI} 2.875-3.578 ; \mathrm{p}<.0001)$

(Table 2).

Table 2: Women's level of education attainment and the number of antenatal visits

\begin{tabular}{|c|c|c|c|c|c|c|c|c|c|c|}
\hline \multirow{3}{*}{ Educational status } & \multirow{3}{*}{$\begin{array}{l}\text { ANC visits } \\
(\mathrm{n}=31,985) \\
44 \text { visits }\end{array}$} & & \multirow{3}{*}{$\begin{array}{l}\text { Bivariate } \\
\text { analysis } \\
\text { Pearson's } \\
\text { Chi-square }\end{array}$} & \multicolumn{7}{|c|}{ Multivariate logistic regression analysis } \\
\hline & & \multirow{2}{*}{$\geq 4$ visits } & & \multirow[t]{2}{*}{ UOR } & \multicolumn{2}{|c|}{$95 \%$ CI for UOR } & \multirow{3}{*}{$\begin{array}{l}\text { AOR } \\
1.00 \\
\end{array}$} & \multirow[t]{2}{*}{$\mathrm{P}$ values } & \multicolumn{2}{|c|}{$95 \% \mathrm{CI}$ for $\mathrm{AOR}$} \\
\hline & & & & & $\begin{array}{l}\text { Lower } \\
\text { limit }\end{array}$ & $\begin{array}{l}\text { Upper } \\
\text { limit }\end{array}$ & & & $\begin{array}{l}\text { Lower } \\
\text { limit }\end{array}$ & $\begin{array}{l}\text { Upper } \\
\text { limit }\end{array}$ \\
\hline None & 10697 & 2111 & $0.001 *$ & 1.00 & & & & & & \\
\hline Primary & 3992 & 2250 & & 2.86 & 2.66 & 3.06 & 2.37 & $0.001 *$ & 2.16 & 2.60 \\
\hline Secondary & 7540 & 2873 & & 1.93 & 1.81 & 2.06 & 3.21 & $0.001 *$ & 2.88 & 3.58 \\
\hline Tertiary & 1768 & 754 & & 2.16 & 1.96 & 2.38 & 2.45 & $0.001 *$ & 2.07 & 2.89 \\
\hline Years of schooling & & & $0.002 *$ & & & & & & & \\
\hline Zero & 10769 & 2150 & & 1.00 & & & 1.00 & & & \\
\hline$<6$ years & 4033 & 2248 & & 2.79 & 2.615 & 2.99 & 3.47 & $0.001 *$ & 2.78 & 3.63 \\
\hline $7-12$ years & 8168 & 3090 & & 1.90 & 1.78 & 2.02 & 17.93 & $0.001 *$ & 10.40 & 21.26 \\
\hline $13+$ & 1027 & 500 & & 2.44 & 2.17 & 2.74 & 12.94 & $0.001 *$ & 4.46 & 36.67 \\
\hline Husband highest education & & & & & & & & & & \\
\hline None & 8654 & 1517 & $0.001 *$ & 1.00 & & & 1.00 & & & \\
\hline Primary & 3044 & 1808 & & 3.39 & 3.13 & 3.67 & 2.03 & 0.10 & 0.6546 & 6.37 \\
\hline Secondary & 2923 & 2916 & & 5.69 & 5.28 & 6.13 & 1.94 & 0.40 & 0.609 & 6.17 \\
\hline Higher & 1392 & 1398 & & 5.73 & 5.223 & 6.28 & 1.79 & 0.20 & 0.567 & 5.67 \\
\hline
\end{tabular}

$* \mathrm{p}$ is significant at the 0.05 level

Note: Variables adjusted in the model: parity, income, religion, age and distance. 
Increasing level of education was observed to be associated with greater percentage of institutional delivery $\left(\chi^{2}=5431.96 ; \mathrm{df}=3 ; \mathrm{p}<0.001\right)$. Women with greater than a primary level of education are twice more likely to deliver in a health facility compared to illiterates after adjusting for covariates (AOR $=2.009$; CI 1.449 - 2.785; $\mathrm{p}<$.0001) (Table 3). The educational status of husbands/ partners was observed to be associated with the use of modern delivery facilities $\left(\chi^{2}=3550.95\right.$; df $=3$; $\mathrm{p}<$ 0.001). Women whose husbands/partners had secondary or higher level of education had 10 fold higher likelihood to deliver in a health facility compared to women whose husbands/partners are uneducated (UOR = 10.529; CI 9.566 - 11.589) (Table 3).

Table 3: Women's Levels of Educational attainment and the Place of Delivery

\begin{tabular}{|c|c|c|c|c|c|c|c|c|c|c|}
\hline & \multicolumn{2}{|c|}{$\begin{array}{l}\text { Place of delivery } \\
(\mathrm{n}=17,949)\end{array}$} & \multirow{2}{*}{$\begin{array}{l}\begin{array}{l}\text { Bivariate } \\
\text { analysis }\end{array} \\
\text { Pearson } \\
\text { Chi-square }\end{array}$} & \multicolumn{7}{|c|}{ Multivariate logistic regression analysis } \\
\hline & Home & Facility & & UOR & $95 \% \mathrm{CI} \mathrm{f}$ & OR & AOR & & $95 \% \mathrm{CI}$ & r AOR \\
\hline Educational status & & & & & $\begin{array}{l}\text { Lower } \\
\text { limit }\end{array}$ & $\begin{array}{l}\text { Upper } \\
\text { limit }\end{array}$ & & $\mathrm{P}$ values & $\begin{array}{c}\text { Lower } \\
\text { limit }\end{array}$ & $\begin{array}{l}\text { Upper } \\
\text { limit }\end{array}$ \\
\hline $\begin{array}{l}\text { Woman's Education } \\
\text { status } \\
\text { None } \\
\text { Primary } \\
\text { Secondary } \\
\text { Tertiary }\end{array}$ & $\begin{array}{c}7878 \\
2425 \\
1378 \\
94\end{array}$ & $\begin{array}{c}951 \\
1622 \\
2764 \\
837\end{array}$ & $0.001^{*}$ & $\begin{array}{c}1.00 \\
5.54 \\
16.62 \\
73.76\end{array}$ & $\begin{array}{l}5.053 \\
15.14 \\
58.99\end{array}$ & $\begin{array}{c}6.075 \\
18.241 \\
92.242\end{array}$ & $\begin{array}{c}1.00 \\
1.332 \\
2.009 \\
4.03\end{array}$ & $\begin{array}{l}0.001 * \\
0.001 * \\
0.001^{*}\end{array}$ & $\begin{array}{l}1.093 \\
1.449 \\
2.358\end{array}$ & $\begin{array}{l}1.79 \\
2.79 \\
6.88\end{array}$ \\
\hline $\begin{array}{l}\text { Husband highest } \\
\text { Education } \\
\text { None } \\
\text { Primary } \\
\text { Secondary } \\
\text { Higher }\end{array}$ & $\begin{array}{c}6376 \\
2212 \\
2071 \\
665\end{array}$ & $\begin{array}{c}736 \\
1372 \\
2517 \\
1277\end{array}$ & $0.001 *$ & $\begin{array}{c}1.00 \\
5.37 \\
10.53 \\
16.64\end{array}$ & $\begin{array}{l}4.85 \\
9.57 \\
14.7\end{array}$ & $\begin{array}{c}5.95 \\
11.55 \\
18.77\end{array}$ & $\begin{array}{c}1.00 \\
1.075 \\
1.11 \\
0.83\end{array}$ & $\begin{array}{c}0.67 \\
0.55 \\
0.356\end{array}$ & $\begin{array}{l}0.77 \\
0.80 \\
0.56\end{array}$ & $\begin{array}{l}1.49 \\
1.54 \\
1.23\end{array}$ \\
\hline
\end{tabular}

\section{Discussion}

Findings of this study demonstrated that educational attainment is an important determinant for the proper use of ante-natal and delivery services with women having higher education found to have higher number of antenatal care visits and modern delivery services. The North Western and North Eastern parts of Nigeria had the lowest utilization rates of MHS. This is partly due to the regions having only a fifth of all women who are literates compared to four-fifths of women in the South Western region $^{35}$ of Nigeria, that had highest MHS utilization rate in this study.

Furthermore, the Northern states of the country had the lowest use of MHS. This is partly due to the fact that of the 7.3 million children who are not attending school, girls accounted for $60 \%$ of these children and majority are from the North Eastern and North Western zones of the country. ${ }^{38}$ Adherence to cultural and religious be- liefs such as girls should be married off in their teens, preference to educate the male child, mal-distribution of schools resulting in longer travel time to reach the nearest school and high poverty are some of the factors responsible for states in the North East and North West level having the lowest level of female literacy. ${ }^{38,39,40}$

The possible consequence of education on female reproductive health comprises late marriage, deferred child bearing, lowering of fertility rate, greater independence on reproductive health choices, independence to freely decide on when and where to seek medical attention without approval from anybody and economic empowerment. Education enhances a woman's ability to communicate effectively with health providers and participate in the decision making process based on the various management options regarding her prevailing reproductive issues $^{41}$. Even though, education is related to personal and family income levels, nevertheless, it is significantly asso- 
ciated with the use of prenatal and natal services when income and wealth family index were controlled, as was the case in this study. This finding was similarly observed in Nigeria ${ }^{11,42}$, Kenya ${ }^{18,24}$, Netherlands ${ }^{22}$, and several other countries ${ }^{17,23}$.

This might be related to the fact that education increases a woman's world view, opportunities for better paying jobs, ability to defend her reproductive health rights and overcome age long negative cultural stereotyping of submissiveness to husband/partner regarding her reproductive health desires and adopt behaviors that enhance her health and wellbeing ${ }^{43}$. Conversely, several studies have reported low utilization of modern maternity services with concomitant high risk of maternal and neonatal morbidity, mortality and disability to be highest among illiterates ${ }^{22,23,24,26}$. Generally, the higher a woman's level of education, the higher her level of autonomy, use of MHS, delay in having children and having fewer number of children which, jointly reduces her risk of dying from pregnancy related complications as reported by studies in Nigeria ${ }^{11,25}$, Namibia ${ }^{26}$ and other parts of the world ${ }^{3,29}$.

Overall, this study showed that educated women have a higher number of antenatal care visits and institutional delivery compared to uneducated women living in a similar setting and economic status. This finding is in variance with studies that have reported that increasing levels of education do not necessarily translate to higher use of health services, because educated persons tend to practice self-treatment and non-compliance with treatment and follow up schedule ${ }^{25}$. It is important to note that the latter study concluded that a population of uneducated minorities had positive attitudes and increased utilization of the medical system when symptoms presented. Nevertheless, increased education improves women's knowledge of high-risk prenatal warning signs and treatment, and ultimately promotes positive attitudes toward health care and utilization of services. A long term investment in girls' education will have a ripple effect of opportunity for better paying jobs, better financial capacity to pay for the cost of obstetric services, higher health cultural capital, high level of autonomy and likelihood to be early adaptors of public health programmes such as family planning and immunization.

\section{Strength of this study}

The strength of this study lies in its large sample size of about 34,000 and the proportionate to probability sam- pling methods. ${ }^{35,36}$ which are pre requisite for high external validity of the findings of any study. ${ }^{44}$ Findings from this study provided better understanding of how education influences the use of MHS after adjusting for the differences in income, religion, availability of skilled health worker, distance to the nearest health facility, age and parity. It highlighted the role of the education sector in improving the use of health services by pregnant women, which will improve planning for any long term upstream public health intervention. Findings have the potential for social change by stimulating discussions among the various leaders in education, health, religious and traditional institutions in order address issues relating to these areas.

\section{Limitations of this study}

The study design was cross-sectional, provided additional information on how education influences the use of MHS and therefore, does not imply causality.The DHS data does not have information on what causes delay to take decision to go to the hospital and factors between taking the decision and reaching the appropriate health facility. The access (geographical, economic or cultural) and school attendance are not even within and between each state of the federation and therefore, might account for the differences in female literacy rate and the use of MHS.

There is the need for further research that will provide additional insights (qualitative studies) on how decisions to seek for MHS were taken at family level, and how geographical, economic and cultural factors influence girls' education and the subsequent use of MHS.

\section{Acknowledgements}

The author extends his sincere thanks to Dr. Chinaro Kennedy; Dr. Hebatullah Tawfik and Dr. Daniel Okenu, all of Walden University, USA, for their immense contribution in all aspects of this work.

\section{Conflict of interest}

None

\section{References}

1. World Health Organization. World Health Statistics 2014. World Health Organization, Geneva, Switzerland, 2014. Retrieved from http://www.who.int/gho/publications/world_health_statistics/2014/en/

2. World Health Organization. World Health Statistics 
2013. World Health Organization, Geneva, Switzerland, 2013. Retrieved from http://www.who.int/gho/publications/world_health_statistics/2013/en/

3. World Health Organization, United Nations Children's Fund, United Nations Population Fund \& the World Bank: Trends in Maternal Mortality: 1990 to 2008 - Estimates developed by WHO, UNICEF, UNFPA, and the World Bank, 2010, World Health Organization, Geneva, Switzerland, 2010. Retrieved from http://whqlibdoc. who.int/publications/2010/9789241500265_eng.pdf

4. World Health Organization: World Health Statistics 2016. World Health Organization, Geneva, Switzerland, 2016. Retrieved from http://www.who.int/gho/publications/world_health_statistics/2016/en/

5. Wirth ME, Balk D, Delamonica E, Storeygard A, Sacks E, Minujin A. Setting the stage for equity-sensitive monitoring of the maternal and child health Millennium Development Goals. Bull World Health Organ. 2006;84:519-527 6. Babalola S. Factors associated with use of maternal health services in Haiti: a multilevel analysis. Revista Panamericana de Salud Pública. 2014; 36(1):1 PubMed -14. Retrieved from http://www.scielosp.org/scielo. php?script $=$ sci_arttext\&pid=S1020-49892014000600001 7. De Allegri M, Ridde V, Louis VR, Sarker M, Tiendrebéogo J, Yé M, et al. Determinants of utilization of maternal care services after the reduction of user fees: a case study from rural Burkina Faso. Health Policy. 2011;99(3):210-218. PubMed

8. Burchardt T, Evans M, Holder H. Measuring inequality: Autonomy the degree of empowerment in decisions about one's own life. Centre for Analysis of Social Exclusion, Oxford University, Oxford, United Kingdom. 2010. Retrieved from https://www.gov.uk/government/ uploads/system/uploads/attachment_data/file/85543/ measuring-autonomy.pdf

9. Fatso JC, Ezeh AC, Essendi H. Maternal Health in poor Resource urban settings: How does women's autonomy influence the utilization of obstetric care services? Reproductive Health. 2009;6:9. PubMed Doi: 10.1186/17424755-6-9.

10. Montagu D, Yamey G, Visconti A, Harding A, Yoong J. Where do poor women in developing countries give birth? A multi-country analysis of demographic and health survey data. Plos one. 2011;6(2):1-8.

11. Fawole AO,Shah A, Fabanwo AO, Adegbola O, Adewunmi AA, Eniayewun AB, et al. Predictors of maternal mortality in institutional deliveries in Nigeria. African Health Science. 2012;12(1):32-40.
12. Shim JK. CulturalHealthCapital:A theoreticalapproach to understanding health care interactions and the dynamics of unequal treatment. Journal of Health and Social Behavior. 2010;51(1):1-15. Doi:10.1177/0022146509361185 13. Kullima AA, Kawuwa MB, Audu BM, Geidam AD, Mairiga AG. Trends in maternal mortality in a tertiary institution in Northern Nigeria. Annals of African Medicine. 2009;8(4):221-4. doi: 10.4103/1596-3519.59575.

14. Guerrier G, Oluyide B, Keramorou M, Grais R. High maternal and neonatal mortality rates in Northern Nigeria: an 8 month observational study. International Journal of Women's Health. 2013;5:495-499.Doi: http:/ /dx.org/10.2147/IJWH.S48179

15. Ibeh CC, Okpala PU. Maternal deaths where do they occur: A survey of health facilities in Abia state, South East Nigeria. Journal of Nursing Education and Practice. 2013;3(3):139-148. Doi: 10.5430/jnep.v3n3p139

16. Nwagha UI, Nwachuckwu D, Dim C, Ibekwe PC, Onyebuchi A. Maternal mortality trend in South East Nigeria: Less than a decade to the Millennium Development Goals. Journal of Women's Health. 2010;19(2):323 PubMed -327. Doi: 10.1089/jwh.2008.1028

17. Ahmed S, Creanga AA, Gillespie DG, Tsui AO. Economic status, education and empowerment: Implication for maternal health services utilization in developing countries. Plos one.. 2010;5(6):e1190.doi:10.1371/journal. pone.0011190

18. Desai M, Howard PAP, Odhiambo FO, Katana A, Ouma P, Hamel M, et al. An analysis of pregnancy related mortality in the KEMRI/CDC health and demographic surveillance system in western Kenya. Plos one. 2013;8(7): e68773. Doi: 10.1371/journal.pone.0068773

19. Ezugwu EC, Agu PU, Nwoke MO, \& Ezugwu FO. Reducing maternal deaths in poor resource setting in Nigeria. Nigerian Journal of clinical practice. 2014;17(1):62 -66. Doi: 10.4103/1119-3077.122842. PubMed

20. Fatso JC, Ezeh AC, Oronje R. Provision and use of maternal health services among urban poor in Kenya: What do we know and what can we do? Journal of Urban Health. 2008;85(3):428-442.

21. Onah HE, Ikeako LC, Iloabachie GC.Factors associated with the utilization of maternal services in Enugu, Southern Nigeria. Social Science \& Medicine. 2006; 63(7):1870 PubMed -1878.

22. Ory BE, van Poppel FWA. Trends and risk factors of maternal mortality in the late nineteenth century Netherlands. The History of the Family. 2013;18(4): 481-509. DOI: 10.1080/1081602X.2013.836457. 
23. Wang W, Alva S, Wang S, Fort A: Levels and trends in the utilization of maternal health services in developing countries. Calverton, Maryland: ICF Macro. 2011. Retrieved from http://www.measuredhs.com/publications/publication- cr26-comparative-reports.cfm

24. Yego F, D’Este C, Byles J, Williams JS, Nyongesa P. Risk factors for maternal mortality in a tertiary hospital in Kenya: A case control study. BMC Pregnancy and Childbirth. 2014;14:38. doi:10.1186/1471-2393-14-38

25. Sharp K, Ross CE, Cockerharn WC. Symptoms, beliefs and the use of physician services among the disadvantaged. Journal of Health and Social Behaviour. 1983;29(9):255-263.

26. Olarenwaju FO. Women empowerment as a determinant for investment in children in selected rural communities in Nigeria. African Research Review, 2013;7(4):138161. doi: http//:dx.doi.org/10.4314/afrrev.7i4.9

27. Babalola S, Fatusi A. Determinants of use of maternal health services in Nigeria - looking beyond individual and household factors. BMC Pregnancy and Childbirth. 2009;9:43. Doi: 10.1186/1471-2393-9-43.

28. Upadhay US, Karasek D. Women's empowerment and ideal family size: An examination of DHS empowerment measures in sub-Saharan Africa. International Perspectives on Sexual and Reproductive Health, 2012; 38(2):78-89. Doi: 10.1363/3807812

29. UNICEF. State of the world's children 2012. UNICEF, New York, USA. 2012. Retrieved from http://www. unicef.org/sowc2012/pdfs/SOWC-2012-Main- Report_ EN_21Dec2011.pdf

30. Patra S. Motherhood in childhood: Addressing reproductive health hazards among adolescent married women in India. Reproductive Health, 2016;13:52. PubMed DOI 10.1186/s12978-016-0171-7

31. Ferre C. Age at first child: Does Education Delay Fertility Timing? The case of Kenya. The World Bank, South Asia Region, Human Development Division, 2009; Policy Research Working Paper 4833. Retrieved from https://openknowledge.worldbank.org/bitstream/handle/10986/4029/WPS4833.pdf?sequence $=1$

32. World Health Organization. Adolescent pregnancy: Making pregnancy safer Notes, 2008;1(1):1-4. Retrieved from http://www.who.int/maternal_child_adolescent/ documents/mpsnnotes_2_lr.pdf

33. Mekonnen Y, Mekonnen M. Factors influencing the use of Maternal health care services in Ethiopia. Journal of Health, Population and Nutrition. 2003;21(4): 374-378.
34. Andersen RM. Revisiting the behavioural model and access to medical care: does it matter? Journal of Health Social Behaviour. 1995;3:1-10.

35. National Population Commission, ICF Macro. Nigeria Demographic and Health Survey. Abuja, Nigeria/ Calverton, MD USA. National Population Commission and ICF Macro. 2009. Retrieved from http://pdf.usaid. gov/pdf_docs/PNADQ923.pdf

36. United State Agency for International Development, ICF Macro. Guide to DHS Statistics: Demographic and Health Survey Methodology. Calverton, Maryland USA: USAID and ICF Macro. 2006. Retrieved from http:// dhsprogram.com/pubs/pdf/DHSG1/Guide_to_DHS_ Statistics_29Oct2012_DHSG1.pdf

37. Fapohunda B, Orobaron N. Factors influencing the selection of delivery with no one present in Northern Nigeria: Implications for policy and programs. International Journal of Women's Health. 2014;6:171- PubMed ;183.Doi: 10.2147/IJWH.S54628.

38. Olukayode AJ, Ayoola AY. Gender disparity in enrolment into basic formal education in Nigeria. Implication for national development. African Research Review. 2015; 9(3): 11-23. DOI: http://dx.doi.org/10.4314/afrrev. v9i3.2

39. Nmadu G, Avidime S, Oguntunde O, Dashe V, Abdulkarim B, Mandara M. Girl Child Education: Rising to the challenge. Afr J Reprod. Health. 2010;14(3): 107 PubMed -112.

40. Okafor VE, Arinze FO. Gender accessibility and equality in education: The implication to manpower in Nigeria. African Research Review. 2012; 6(3): 284-290. DOI: http://dx.doi.org/10.4314/afrrev.v6i3.21

41. Shim JK.CulturalHealthCapital:A theoreticalapproach to understanding health care interactions and the dynamics of unequal treatment. Journal of Health and Social Behavior. 2010; 51(1):1-15.Doi:10.1177/0022146509361185 42. Ononokpono DN, Odimegwu CO. Determinants of maternal health care utilization in Nigeria: a multilevel approach. Pan African Medical Journal. 2014. 17(Supp 1):2. Doi:10.11694/pamj.supp.2014.17.1.3596 PubMed

43. Acharya DR, Bell JS, Simkhada P, vanTeijlingen ER, Regmi PR. Women's autonomy in household decision making: A demographic study in Nepal. Reproductive Health. 2010;7:15. PubMed Doi: 10.1186/1742-4755-715

44. Szklo M, Nieto FJ. Understanding a Lack of Validity: Bias in Epidemiology: Beyond the basics (3rd ed.). Sudbury, MA: Jones and Bartlett. 2014. 